Article

\title{
Effect of pH-Responsive Charge-Conversional Polymer Coating to Cationic Reduced Graphene Oxide Nanostructures for Tumor Microenvironment-Targeted Drug Delivery Systems
}

\author{
Kitae Ryu ${ }^{1}$, Jaehong Park ${ }^{1}$ and Tae-il Kim ${ }^{1,2, *}$ (1) \\ 1 Department of Biosystems \& Biomaterials Science and Engineering, College of Agriculture and Life Sciences, \\ Seoul National University, 1 Gwanak-ro, Gwanak-gu, Seoul 08826, Korea \\ 2 Research Institute of Agriculture and Life Sciences, Seoul National University, 1 Gwanak-ro, Gwanak-gu, \\ Seoul 08826, Korea \\ * Correspondence: seal1004@snu.ac.kr
}

Received: 24 July 2019; Accepted: 6 September 2019; Published: 9 September 2019

\begin{abstract}
Tumor tissue represents a slightly acidic $\mathrm{pH}$ condition compared to normal tissue due to the accumulation of lactic acids via anaerobic metabolism. In this work, $\mathrm{pH}$-responsive charge-conversional polymer (poly(ethylene imine)-poly(L-lysine)-poly(L-glutamic acid), PKE polymer) was employed for endowing charge-conversional property and serum stability to poly(ethylene imine) conjugated reduced graphene oxide-based drug delivery system (PEI-rGO). Zeta-potential value of PEI-rGO coated with $\mathrm{PK}_{5} \mathrm{E}_{7}$ polymer $\left(\mathrm{PK}_{5} \mathrm{E}_{7}(\mathrm{PEI}-\mathrm{rGO})\right.$ ) was $-10.9 \mathrm{mV}$ at $\mathrm{pH} 7.4$ and converted to $29.2 \mathrm{mV}$ at $\mathrm{pH}$ 6.0, showing $\mathrm{pH}$-responsive charge-conversional property. Sharp-edged plate morphology of PEI-rGO was transformed to spherical nanostructures with vague edges by $\mathrm{PK}_{5} \mathrm{E}_{7}$ coating. Size of $\mathrm{PK}_{5} \mathrm{E}_{7}$ (PEI-rGO) was found to be smaller than that of PEI-rGO in the serum condition, showing its increased serum stability. Loaded doxorubicin (DOX) in $\mathrm{PK}_{5} \mathrm{E}_{7}$ (PEI-rGO) could be released rapidly in lysosomal condition ( $\mathrm{pH}$ 5.0, $5 \mathrm{mM}$ glutathione). Furthermore, DOX-loaded $\mathrm{PK}_{5} \mathrm{E}_{7}$ (PEI-rGO) showed enhanced anticancer activity in HeLa and A549 cells in the tumor microenvironment-mimicking condition ( $\mathrm{pH}$ 6.0, serum), which would be mediated by non-specific cellular interaction with decorated serum proteins. These results indicate that the pH-responsive charge-conversional PKE polymer coating strategy of cationic rGO nanostructures possesses a potential for acidic tumor microenvironment-targeted drug delivery systems.
\end{abstract}

Keywords: $\mathrm{pH}$-responsive charge-conversion; polymer coating; graphene oxide; drug delivery systems; doxorubicin; serum stability

\section{Introduction}

The tumor microenvironment does not simply refer to cancer cell clusters but also to the cancer-associated fibroblasts, myoblasts, epithelial cells, and immune cells along with the extracellular matrix (ECM), oxygen level, $\mathrm{pH}$, and so on [1-4]. Cancer cells surrounded by the tumor microenvironment affect the cell growth, migration, neovascularization, and metastasis by secretion of growth factors as well as ECM degradation enzyme. Tumor tissue has a deficiency of oxygen and nutrition due to the rapid growth of cancer cells. Consequently, the tumor microenvironment turns to an acidic condition as the tissue metabolism progresses under anaerobic condition [5-7]. Therefore, accurate delivery of therapeutic drugs or genes to the target lesion based on the recognition of the acidic tumor microenvironment became an important research field for the development of gene or drug delivery systems and the treatment of cancer. 
The main component that constitutes the serum protein is negatively-charged albumin [8]. Therefore, conventional cationic gene or drug delivery systems are prone to aggregate with negatively-charged serum protein due to the electrostatic interaction and to be eliminated via renal clearance or reticuloendothelial system [9]. In order to overcome this problem and utilize the acidic condition of the tumor microenvironment, the various strategies about gene or drug delivery systems using $\mathrm{pH}$-responsive polymers have been pursued. In particular, maleic acid amide derivatives conjugated to amine groups which have $\mathrm{pH}$-responsive charge-conversion ability [10-17], acid-labile linkages such as a hydrazone bond [18-21], and polypeptides which are composed of both cationic amino acids and anionic amino acids [22-27] have been utilized for gene or drug delivery systems. As a result, it is expected that these polymeric gene or drug delivery systems can enhance the delivery efficiency, shielding the interaction with negatively-charged serum proteins under normal physiological $\mathrm{pH}$ conditions and improving the cellular uptake by conversion to positively-charged systems through the specific $\mathrm{pH}$-responsive charge-conversion behaviors in the acidic tumor environment (hydrolysis, protonation/deprotonation, etc.).

Graphene is a carbon-based material having a flat two-dimensional monolayer of the hexagonal honeycomb structure [28]. To obtain graphene nanosheets, the graphite oxide is prepared by Hummers' method [29] and treated with ultrasonication to separate graphite oxide into a single layer of graphene oxide. The graphene oxide (GO) has various hydrophilic functional groups, such as hydroxyl groups $(-\mathrm{OH})$, epoxide groups (-O-), and carboxyl groups (-COOH), which show high water dispersibility, chemical modifiability, and good biocompatibility. In addition, GO-based nanomaterials could be applied as hydrophobic drug delivery platforms due to their inherent characteristics in terms of drug loading via hydrophobic or $\pi-\pi$ stacking interaction [30,31]. Especially, a GO derivative modified with branched poly(ethylene imine) (BPEI-GO) has been developed for gene delivery systems with low cytotoxicity and high transfection efficiency [32]. BPEI-GO also showed the potential as a bioimaging sensor due to its photoluminescence. In addition, poly(ethylene glycol)-conjugated PEI-modified reduced graphene oxide (PEG-BPEI-rGO) was synthesized for drug delivery systems [33]. It possessed much higher doxorubicin (DOX) loading efficiency than non-reduced derivative, PEG-BPEI-GO and showed high anticancer activity due to efficient endosome escape by endosome buffering and photothermal disruption of endosome membrane, and fast release of DOX by intracellular glutathione (GSH) and photothermal effect via near-infrared radiation.

Therefore, we assumed that this PEI-rGO-based nano drug delivery system would acquire the serum-resistance and the cancer cell killing ability, responding to acidic tumor microenvironment condition by coating with $\mathrm{pH}$-responsive charge-conversional polymers.

Here, we used poly(ethylene imine)-poly(L-lysine)-poly(L-glutamic acid)s (PKE polymers) with various composition ratios of cationic amino acids and anionic amino acids as $\mathrm{pH}$-responsive charge-conversional polymers [27] for the coating of PEI-rGO. PKE polymer nanostructures showed $\mathrm{pH}$-responsive charge-conversion from negative charge at $\mathrm{pH} 7.4$ to positive charges at $\mathrm{pH} 6.0$, according to the protonation/deprotonation behavior of their lysine and glutamic acid residues. DOX was also employed as a drug molecule due to its feasible loading onto PEI-rGO nanostructures. DOX is a well-known anthracycline antibiotic with antineoplastic activity, which is isolated from the bacterium Streptomyces peucetius caesius [34].

In this study, we loaded DOX onto PEI-rGO and coated DOX-loaded PEI-rGO with PKE polymers, forming PKE(PEI-rGO/DOX) nanostructures. Then, physicochemical properties, serum stability, DOX release profile, and anticancer activity of PKE polymer-coated PEI-rGO/DOX nanostructures were examined based on $\mathrm{pH}$-responsive charge-conversion ability.

\section{Materials and Methods}

\subsection{Materials}

Poly(ethylene imine) $1.8 \mathrm{kDa}$ (branched, $\mathrm{PEI}_{1.8 \mathrm{k}}$ ) and L-glutathione (GSH) were purchased from Alfa Aesar (Haverhill, MA, USA). H-Lys(Z)-OH (Lys(Z)), L-Glutamic acid $\gamma$-benzyl ester (BGlu), 
trifluoroacetic acid, triphosgene, hydrobromic acid solution (33 wt $\%$ in acetic acid), agarose, and ethylenediaminetetraacetic acid (EDTA) were purchased from Sigma-Aldrich (St. Louis, MO, USA). Dimethylsulfoxide (DMSO), sodium chloride, and tris base were purchased Merck (Darmstadt, Germany). $\mathrm{D}_{2} \mathrm{O}$ and trifluoroacetic acid-D were purchased Cambridge Isotope Laboratories (Tewksbury, MA, USA). Tetrahydrofuran was purchased from Tokyo Chemical Industry (Tokyo, Japan). Doxorubicin (DOX) was purchased from Tocris Bioscience (Bristol, UK). Diethyl ether and n-hexane were purchased from Daejung (Siheung, Korea). Thiazolyl blue tetrazolium bromide was purchased from Gold Bio (St. Louis, MO, USA). Dulbecco's Modified Eagles' Medium (1X) + GlutaMAX-1 (DMEM), Dulbecco's Phosphate Buffered Saline (DPBS), 0.25\% Trypsin-EDTA, fetal bovine serum (FBS), and Penicillin-Streptomycin (Pen Strep, P/S) were purchased from Invitrogen-Gibco (Carlsbad, CA, USA). All other chemicals were purchased and used without any further purification.

\subsection{Synthesis of PKE Polymers}

PKE polymers were synthesized using $\mathrm{PEI}_{1.8 \mathrm{k}}$ as a macroinitiator by ring-opening polymerization of amino acid N-carboxyanhydride (NCA) as previously described [27]. Briefly, Lys(Z)-NCA and BGlu-NCA monomer were prepared using triphosgene ring formation reaction. Lys(Z)-NCA (50 molar excess to PEI) was reacted with $\mathrm{PEI}_{1.8 \mathrm{k}}$ to synthesize $\mathrm{PEI}_{1.8 \mathrm{k}}$-polyLys $(\mathrm{Z}$ ) and subsequently, BGlu-NCA (50, 70, 90, or 130 molar excess to PEI) was reacted with $\mathrm{PEI}_{1.8 \mathrm{k}}$-polyLys(Z) to synthesize $\mathrm{PEI}_{1.8 \mathrm{k}}$-polyLys(Z)-polyBGlu. After removal of protecting groups, poly(ethylene imine)-poly(L-lysine)-poly(L-glutamic acid)s (PKE polymers) were obtained. The synthesized PKE polymers were named as $\mathrm{PK}_{5} \mathrm{E}_{5}, \mathrm{PK}_{5} \mathrm{E}_{7}, \mathrm{PK}_{5} \mathrm{E}_{9}$, and $\mathrm{PK}_{5} \mathrm{E}_{13}$, respectively, based on the ratios of conjugated L-lysine and L-glutamic acid moieties to $\mathrm{PEI}_{1.8 \mathrm{k}}$.

\subsection{Preparation of DOX-Loaded PEI-rGO (PEI-rGO/DOX)}

PEI-conjugated reduced graphene oxide (PEI-rGO) [33] was kindly provided by Prof. Won Jong Kim in Pohang University of Science and Technology, Korea. DOX was dissolved in DMSO at a concentration of $5 \mathrm{mg} / \mathrm{mL}$. The DOX/DMSO solution (50 wt $\%$ to PEI-rGO) was slowly added to the PEI-rGO solution. The mixture solution was shaken for $12 \mathrm{~h}$ in dark condition. Then, dialysis (MWCO: 3000) was performed for $24 \mathrm{~h}$ to remove unbound DOX. Finally, PEI-rGO/DOX was obtained through centrifugation ( $4000 \mathrm{rpm}, 20 \mathrm{~min}, 25^{\circ} \mathrm{C}$ ) using Amicon Ultra-4 centrifugal filters $3 \mathrm{~K}$ (Merck, Germany).

The DOX loading in PEI-rGO was confirmed by measuring absorbance (300-700 nm) of PEI-rGO and PEI-rGO/DOX respectively, using a microplate reader (Synergy H1, BioTek, Winooski, VT, USA). The DOX loading efficiency was examined by measuring DOX fluorescence (Ex: 480 nm, Em: 520-700 nm) of PEI-rGO/DOX in water or 90\% DMSO. Ten microliters (10 $\mu \mathrm{L})$ of PEI-rGO/DOX solution (1 mg/mL PEI-rGO) was added to $90 \mu \mathrm{L}$ of water or DMSO. The DOX loading amount was calculated by comparison of DOX fluorescence values measured in water and 90\% DMSO. DOX loading efficiency was calculated as below:

Drug loading efficiency (DLE, \%)

$$
=\left(\frac{\text { Weight of loaded DOX }(\mathrm{mg})}{\text { Weight of total DOX for loading }(\mathrm{mg})}\right) \times 100
$$

\subsection{Preparation of PKE Polymer-Coated PEI-rGO (PKE(PEI-rGO)) and PKE Polymer-Coated PEI-rGO/DOX $(P K E(P E I-r G O / D O X))$}

To form PKE(PEI-rGO) or PKE(PEI-rGO/DOX) nanostructures, PEI-rGO or PEI-rGO/DOX solution (deionized water) were added to PKE polymer solutions (deionized water) having pre-determined weight ratios (PKE:PEI-rGO = 10:1, 20:1, 30:1, or 50:1, w/w) by dropwise, respectively. The mixtures were incubated for $1 \mathrm{~h}$ with orbital shaking at room temperature. Then, they were centrifuged (4000 rpm, $10 \mathrm{~min}$, room temperature) and re-dispersed in solutions after removal of supernatants. 


\subsection{Characterization of PEI-rGO Based Nanostructures}

The average sizes and zeta-potential values of the prepared PKE(PEI-rGO) and PKE(PEI-rGO/DOX) nanostructures were measured by using a Zeta-sizer Nano ZS90 (Malvern Instruments, Malvern, UK). First, the average sizes and zeta-potential values of PKE polymer-coated PEI-rGOs (PKE(PEI-rGO)) with various PKE polymer weight ratios (10, 20, 30, or 50) were measured. Additionally, the average size and zeta-potential value of each PKE(PEI-rGO) nanostructure (weight ratio = 30) were measured at $\mathrm{pH} 7.4$ and $\mathrm{pH}$ 6.0. Additionally, the average sizes and zeta-potential values of $\mathrm{PK}_{5} \mathrm{E}_{7}(\mathrm{PEI}-\mathrm{rGO} / \mathrm{DOX})$ and $\mathrm{PK}_{5} \mathrm{E}_{9}(\mathrm{PEI}-\mathrm{rGO} / \mathrm{DOX})$ (weight ratio $=30$ ) were measured at $\mathrm{pH} 7.4$ and $\mathrm{pH} 6.0$ to examine the property change after DOX loading to the PEI-rGO.

The energy filtered transmission electron microscope (EF-TEM) was used to observe the morphology of PEI-rGO and PEI-rGO/DOX nanostructures with and without $\mathrm{PK}_{5} \mathrm{E}_{7}$ polymer coating (weight ratio $=30)$. The samples were absorbed onto TEM copper grid. After drying for $12 \mathrm{~h}$ and the images were visualized by EF-TEM (LIBRA 120, Carl Zeiss, Oberkochen, Germany) under the voltage of $80 \mathrm{kV}$.

\subsection{Serum Stability of PKE Polymer Coated PEI-rGO (PKE(PEI-rGO))}

The nanostructure stability in serum condition was investigated by measuring the size changes of PEI-rGO based nanostructures. PEI-rGO or PK ${ }_{5} \mathrm{E}_{7}(\mathrm{PEI}-\mathrm{rGO}$ ) was centrifuged (4000 rpm, $10 \mathrm{~min}$, room temperature) and dispersed in PBS or PBS containing 10\% FBS at pH 7.4 or 6.0. Each sample was incubated at $37^{\circ} \mathrm{C}$ with gentle shaking. After pre-determined incubation time $(2,4,8,16$, and $24 \mathrm{~h})$, the average size of each sample was measured using Zeta-sizer.

\subsection{DOX Release Profile of $\mathrm{PK}_{5} E_{7}(\mathrm{PEI}-\mathrm{rGO} / \mathrm{DOX})$}

DOX release profile of $\mathrm{PK}_{5} \mathrm{E}_{7}$ coated PEI-rGO/DOX was examined. One-hundred micrograms $(100 \mu \mathrm{g})$ of $\mathrm{PK}_{5} \mathrm{E}_{7}(\mathrm{PEI}-\mathrm{rGO} / \mathrm{DOX})$ (weight ratio = 30) was prepared for measuring DOX release. The total volume of $\mathrm{PK}_{5} \mathrm{E}_{7}(\mathrm{PEI}-\mathrm{rGO} / \mathrm{DOX})$ solution was adjusted to $2 \mathrm{~mL}$ and the solution was placed in a dialysis membrane (MWCO: 3000) in $50 \mathrm{~mL}$ of PBS (pH 7.4, pH 5.0, or pH 5.0 with $5 \mathrm{mM}$ of glutathione). The solutions were incubated at $37^{\circ} \mathrm{C}$ with gentle shaking in dark condition. After pre-determined incubation time $(0.5,1,2,4,8,12$, and $24 \mathrm{~h})$, released DOX amount was analyzed by measuring the DOX fluorescence outside the membrane $(\mathrm{Ex}=480 \mathrm{~nm}, \mathrm{Em}=560 \mathrm{~nm})$ using a microplate reader.

\subsection{Anticancer Activity of $\mathrm{PK}_{5} E_{7}(\mathrm{PEI}-\mathrm{rGO} / \mathrm{DOX})$}

Anticancer activity of $\mathrm{PK}_{5} \mathrm{E}_{7}(\mathrm{PEI}-\mathrm{rGO} / \mathrm{DOX})$ was examined by MTT assay in human cervical adenocarcinoma cells (HeLa cells) and human lung adenocarcinoma epithelial cells (A549 cells). HeLa and A549 cells were cultured in DMEM with 10\% FBS and 1\% penicillin/streptomycin (P/S) $\left(37^{\circ} \mathrm{C}, 5 \%\right.$ $\mathrm{CO}_{2}$ ). Cells were seeded at $1 \times 10^{4}$ cells/well on 96-well cell culture plates and cultured for $24 \mathrm{~h}$. After reaching $70-80 \%$ of cell confluency, the $\mathrm{pH}$ of the medium was adjusted to $\mathrm{pH} 7.4$ or 6.0. One-hundred microliters $(100 \mu \mathrm{L})$ of $\mathrm{PK}_{5} \mathrm{E}_{7}(\mathrm{PEI}-\mathrm{rGO} / \mathrm{DOX})$ solution $(10,20$, or $50 \mu \mathrm{g} / \mathrm{mL}$ DOX) was treated to each well and incubated for $24 \mathrm{~h}$. DOX only, $\mathrm{PK}_{5} \mathrm{E}_{7}$, and $\mathrm{PK}_{5} \mathrm{E}_{7}(\mathrm{PEI}-\mathrm{rGO})$ with various concentration ( $\mathrm{pH}$ 7.4) were also treated to HeLa cells or A549 cells as controls. Then, each medium was replaced with fresh medium containing 10\% FBS and 1\% P/S. After further incubation for $24 \mathrm{~h}, 25 \mu \mathrm{L}$ of MTT/DPBS solution $(2 \mathrm{mg} / \mathrm{mL})$ was added to each well and incubated for $2 \mathrm{~h}$. The medium was carefully removed and $150 \mu \mathrm{L}$ of DMSO was added to the formazan crystal formed by proliferating cells. The absorbance at $570 \mathrm{~nm}$ was measured using a microplate reader. The anticancer activity was expressed as the relative cell viability (\%) by comparing the absorbance values with cell only value.

\subsection{Cellular Uptake of PKE Polymer Coated PEI-rGO/DOX}

The cellular uptake efficiency of $\mathrm{PK}_{5} \mathrm{E}_{7}(\mathrm{PEI}-\mathrm{rGO} / \mathrm{DOX}$ ) (weight ratio = 30) was evaluated by flow cytometry analysis in HeLa and A549 cells. Cells were seeded at a density of $2 \times 10^{5}$ cells/well 
on six-well cell culture plates. Having achieved $70-80 \%$ of confluency, the cells were treated with $\mathrm{PK}_{5} \mathrm{E}_{7}$ (PEI-rGO/DOX) solutions in serum-free or serum-containing medium (pH 7.4 or 6.0) for $4 \mathrm{~h}$, respectively. Then, the cells were washed twice with ice-cold DPBS and detached using trypsin-EDTA. The cells were resuspended in DPBS and analyzed by FACS using BD Accuri C6 flow cytometer (Becton Dickinson Biosciences, San Jose, CA, USA) at a minimum of $1 \times 10^{4}$ cells gated per sample. The flow cytometry results were processed by Flowing software (Cell Imaging Core, Turku Centre for Biotechnology, Turku, Finland).

\subsection{Fluorescence Microscopy Observation of $P K_{5} E_{7}(P E I-r G O / D O X)$}

A549 cells were seeded at a density of $2 \times 10^{5}$ cells/well on six-well cell culture plates. Having achieved $70-80 \%$ of confluency, the cells were treated with $\mathrm{PK}_{5} \mathrm{E}_{7}(\mathrm{PEI}-\mathrm{rGO} / \mathrm{DOX})$ solutions $(10 \mu \mathrm{g} / \mathrm{mL}$ DOX) in serum-free or serum-containing medium ( $\mathrm{pH} 7.4$ or 6.0) for $24 \mathrm{~h}$, respectively. Then, the cells were washed twice with ice-cold DPBS and stained with Hoechst $33342(10 \mu \mathrm{g} / \mathrm{mL})$ for $15 \mathrm{~min}$. After washing with DPBS twice, fluorescence images were observed by fluorescence microscope (iRiS Digital Cell Imaging System, Logos Biosystems, Anyang, Korea).

\section{Results and Discussions}

\subsection{Formation of PKE Polymer Coated PEI-rGO (PKE(PEI-rGO))}

According to the previous study [27], it was confirmed that 51.8 L-lysine residues were conjugated to one PEI1.8k molecule and conjugated L-glutamic acid residues in PKE polymers were 53.4, 75.9, 93.7, and 140.5 molecules per one PEI1.8k molecule, respectively. According to the ratios of conjugated L-lysine and L-glutamic acid moieties to PEI1.8k, PKE polymers were named as $\mathrm{PK}_{5} \mathrm{E}_{5}, \mathrm{PK}_{5} \mathrm{E}_{7}, \mathrm{PK}_{5} \mathrm{E}_{9}$, and $\mathrm{PK}_{5} \mathrm{E}_{13}$, respectively. PKE polymers showed $\mathrm{pH}$-responsive charge-conversional ability, according to the protonation/deprotonation behavior of their lysine and glutamic acid residues responding to environmental $\mathrm{pH}$ change. For example, the zeta-potential value of $\mathrm{PK}_{5} \mathrm{E}_{9}$ polymer particle was increased from $-35.0 \mathrm{mV}$ to $27.5 \mathrm{mV}$ as $\mathrm{pH}$ was decreased from 10.0 to 3.0. This change could induce the increase of both cellular uptake and serum stability in terms of gene delivery systems. The inherent characteristics of the $\mathrm{pH}$-responsive charge-conversional ability of PKE polymers could be regulated via controlling the ratios between L-lysine and L-glutamic acid residues.

Therefore, it was assumed that we would modulate the physicochemical properties of PEI-rGO by coating with PKE polymers via electrostatic interaction for improvement of serum stability and anticancer efficacy responding to environmental $\mathrm{pH}$.

First, Z-average sizes and zeta-potential values of PKE(PEI-rGO) nanostructures with various weight ratios between PKE and PEI-rGO were measured to examine the PKE coating effect to PEI-rGO. It was found that intact PEI-rGO without coating had about $200 \mathrm{~nm}$ size and $50 \mathrm{mV}$ zeta-potential value.

As shown in Figure 1A, the sizes of $\mathrm{PK}_{5} \mathrm{E}_{5}$ (PEI-rGO) were gradually increased from $204.7 \mathrm{~nm}$ to $681.3 \mathrm{~nm}$ with the increase of weight ratios from 10 to 30 and then decreased to $272.5 \mathrm{~nm}$ at a weight ratio of 50. Zeta-potential values of $\mathrm{PK}_{5} \mathrm{E}_{5}$ (PEI-rGO) were gradually decreased from $38.7 \mathrm{mV}$ to $22.7 \mathrm{mV}$ with the increase of the weight ratios from 10 to 50 . In the case of $\mathrm{PK}_{5} \mathrm{E}_{7}$ coating to PEI-rGO (Figure 1B), the sizes were maintained under $300 \mathrm{~nm}$ at weight ratios of 10-30 (225.1 277.1 nm) and the size was greatly increased at a weight ratio of $50(590.6 \mathrm{~nm})$. In Figure S1, it was found that $\mathrm{PK}_{5} \mathrm{E}_{7}(\mathrm{PEI}-\mathrm{rGO})$ showed homogeneous size distributions, regardless of weight ratios. Their zeta-potential values were reduced from 27.4 to $20.5 \mathrm{mV}$ with the increase of weight ratios from 10 to 50 . The size of $\mathrm{PK}_{5} \mathrm{E}_{9}$ (PEI-rGO) was the largest $(718.5 \mathrm{~nm}$ ) at a weight ratio of 20 (Figure 1C). At weight ratios of 30 and 50, the sizes were gradually decreased to $495.0 \mathrm{~nm}$ and $198.0 \mathrm{~nm}$, respectively. $\mathrm{PK}_{5} \mathrm{E}_{9}$ (PEI-rGO) showed zeta potential value of -35.0 at a weight ratio of 10 , which remained unchanged significantly $(-32.8 \sim-31.8 \mathrm{mV})$ regardless of weight ratios. $\mathrm{PK}_{5} \mathrm{E}_{13}($ PEI-rGO) displayed sizes less than $250 \mathrm{~nm}$ $(113.03 \sim 246.6 \mathrm{~nm})$ and zeta-potential values maintaining negative values $(-40.3 \sim-37.0 \mathrm{mV})$, regardless of weight ratios (Figure 1D). 

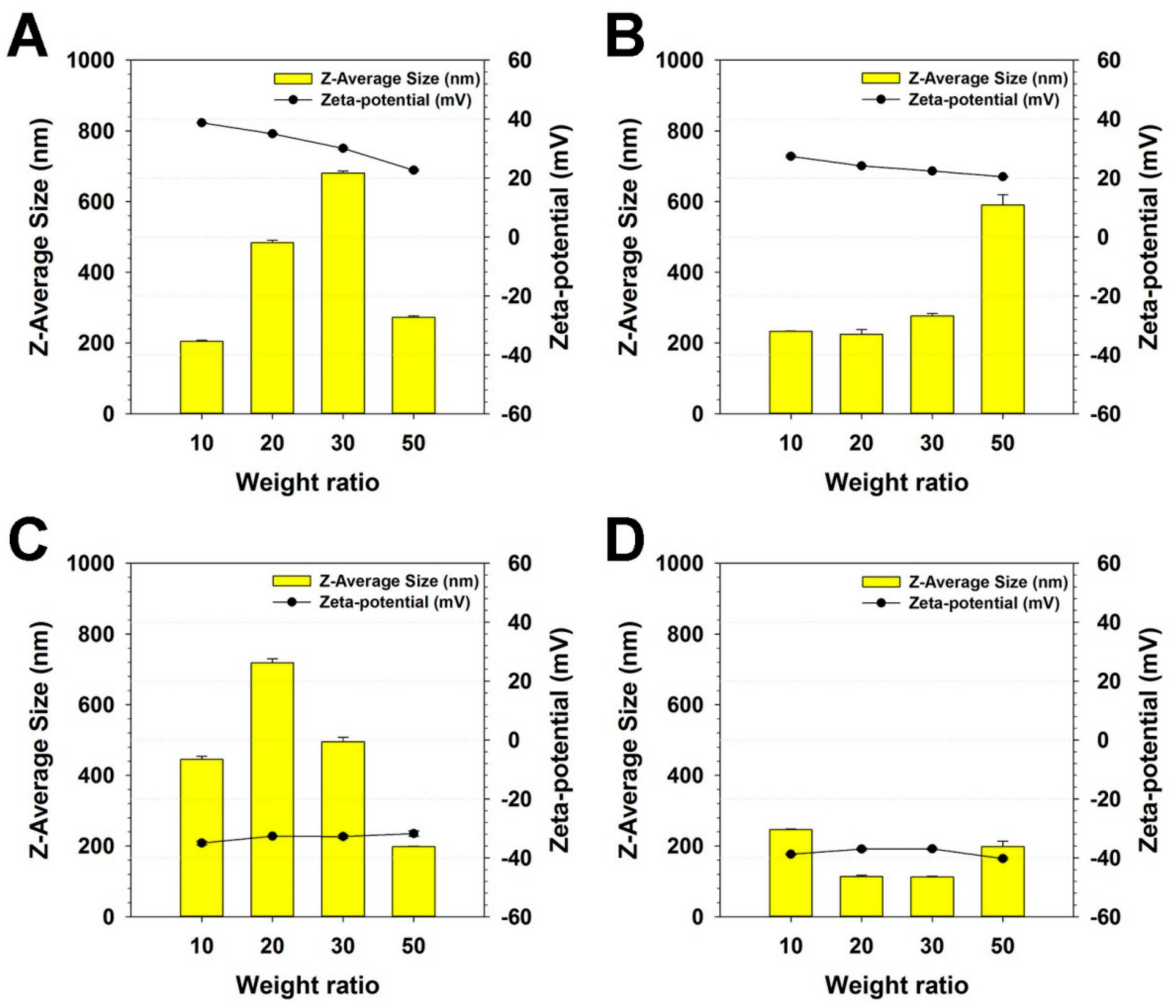

Figure 1. Z-Average sizes and zeta-potential values of (A) $\mathrm{PK}_{5} \mathrm{E}_{5}(\mathrm{PEI}-\mathrm{rGO}),(\mathbf{B}) \mathrm{PK}_{5} \mathrm{E}_{7}(\mathrm{PEI}-\mathrm{rGO}),(\mathbf{C})$ $\mathrm{PK}_{5} \mathrm{E}_{9}(\mathrm{PEI}-\mathrm{rGO})$, and (D) $\mathrm{PK}_{5} \mathrm{E}_{13}$ (PEI-rGO) with various weight ratios (PKE:PEI-rGO). Data are shown as the mean \pm S.D $(n=3)$.

These results suggested that PKE(PEI-rGO) nanostructures could form aggregates at certain coating weight ratios of PKE polymers, which were dependent on PKE polymer types. It is thought that PKE polymers with different cationic lysine and anionic glutamic acid ratios, which means the different net charges and chain lengths, would act as electrostatic glues between the nanostructures for aggregate formation during coating process [35].

Decreased zeta-potential values of $\mathrm{PK}_{5} \mathrm{E}_{5}(\mathrm{PEI}-\mathrm{rGO})$ and $\mathrm{PK}_{5} \mathrm{E}_{7}(\mathrm{PEI}-\mathrm{rGO})$ with the increase of PKE weight ratios mean that anionic glutamic acid residues of PKE polymers would induce the negative surface charges to PEI-rGO by coating. In the case of $\mathrm{PK}_{5} \mathrm{E}_{9}$ (PEI-rGO) and $\mathrm{PK}_{5} \mathrm{E}_{13}$ (PEI-rGO), their negative zeta-potential values mean that negative charges from glutamic acid residues exceed positive charges from lysine residues due to their having more anionic moieties (carboxylic acid of glutamic acid) than cationic moieties (amine of PEI and lysine).

\section{2. $p H$-Responsive Charge-Conversional Ability of PKE(PEI-rGO)s}

It was expected that PKE(PEI-rGO) nanostructures would possess $\mathrm{pH}$-responsive charge-conversional property, which means the maintenance of negatively charged surfaces at normal physiological $\mathrm{pH}$, conferring serum stability and conversion to a positively charged surfaces in mild acidic condition like tumor microenvironment, providing improved adsorption to negatively-charged cellular membrane and cellular uptake. Therefore, Z-average sizes and zeta-potential values of PKE(PEI-rGO) nanostructures were examined at $\mathrm{pH} 7.0$ and 6.4.

As shown in Figure $2 \mathrm{~A}$, the size of $\mathrm{PK}_{5} \mathrm{E}_{5}(\mathrm{PEI}-\mathrm{rGO})$ at $\mathrm{pH} 7.4(548.7 \mathrm{~nm})$ was slightly decreased to $459.0 \mathrm{~nm}$ at $\mathrm{pH}$ 6.0, while its zeta-potential at $\mathrm{pH} 7.4(21.2 \mathrm{mV})$ was increased to $37.6 \mathrm{mV}$ at $\mathrm{pH}$ 6.0. $\mathrm{PK}_{5} \mathrm{E}_{7}$ (PEI-rGO) presented $1425.7 \mathrm{~nm}$ size probably due to the aggregates formation during coating process and $-10.9 \mathrm{mV}$ zeta-potential value at $\mathrm{pH} 7.4$ (Figure 2B). However, its size was dramatically decreased to $164.3 \mathrm{~nm}$ and the zeta-potential was converted to positive value $(29.2 \mathrm{mV})$ at $\mathrm{pH} 6.0$. In Figure $2 \mathrm{C}, \mathrm{PK}_{5} \mathrm{E}_{9}$ (PEI-rGO) exhibited $235.2 \mathrm{~nm}$ size and $-30.8 \mathrm{mV}$ zeta-potential value at $\mathrm{pH}$ 7.4. 
At $\mathrm{pH}$ 6.0, its size was increased to $661.6 \mathrm{~nm}$ and the zeta-potential value was $6.0 \mathrm{mV}$. In the case of $\mathrm{PK}_{5} \mathrm{E}_{13}(\mathrm{PEI}-\mathrm{rGO})$, the size (about $150 \mathrm{~nm}$ ) and the zeta-potential value $(-35.6 \sim-31.8 \mathrm{mV}$ ) were not significantly changed, regardless of $\mathrm{pH}$.
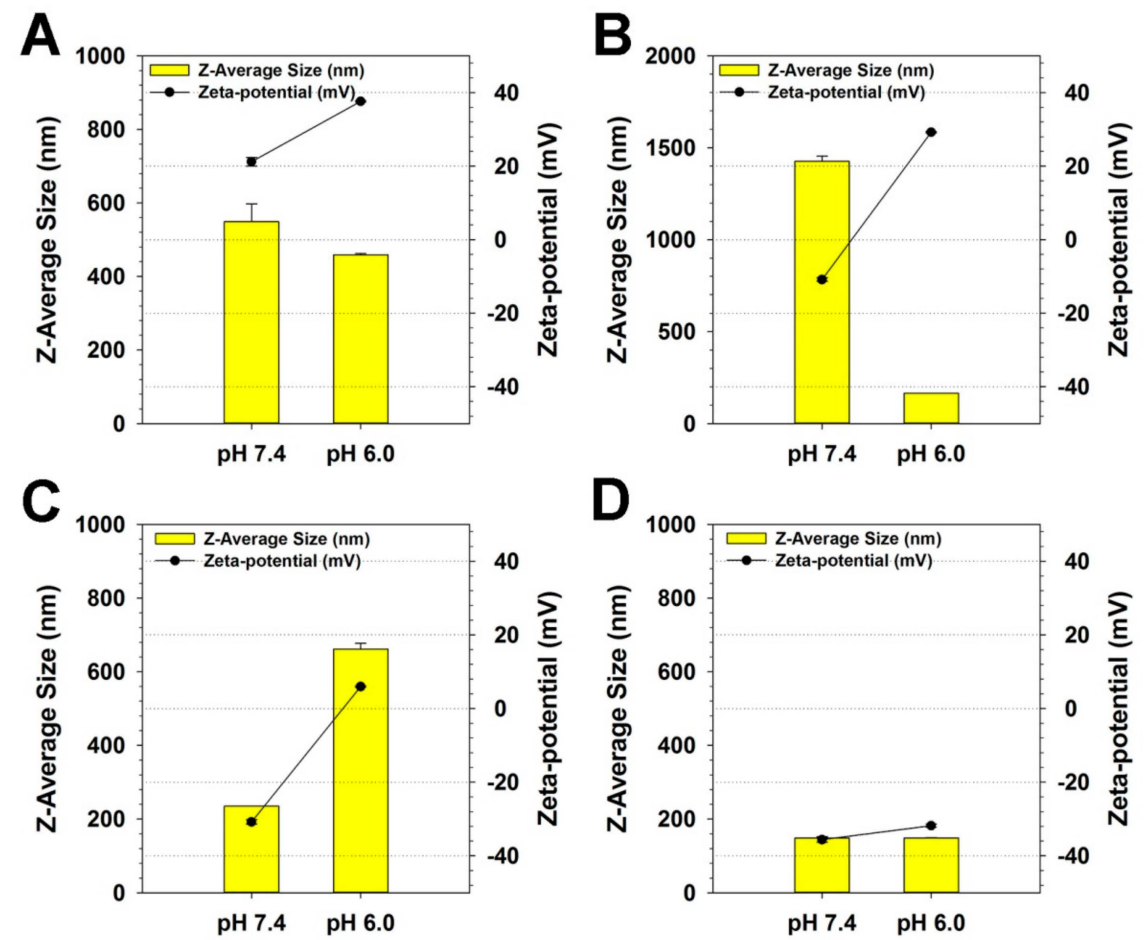

Figure 2. Z-average sizes and zeta-potential values of PKE(PEI-rGO) nanostructures at $\mathrm{pH} 7.4$ and 6.0. (A) $\mathrm{PK}_{5} \mathrm{E}_{5}$ (PEI-rGO), (B) $\mathrm{PK}_{5} \mathrm{E}_{7}$ (PEI-rGO), (C) $\mathrm{PK}_{5} \mathrm{E}_{9}$ (PEI-rGO), and (D) $\mathrm{PK}_{5} \mathrm{E}_{13}$ (PEI-rGO). The PKE polymer coating ratio was set to a weight ratio of 30 . Data are shown as the mean \pm S.D $(n=3)$.

These results indicated that only $\mathrm{PK}_{5} \mathrm{E}_{7}(\mathrm{PEI}-\mathrm{rGO})$ and $\mathrm{PK}_{5} \mathrm{E}_{9}(\mathrm{PEI}-\mathrm{rGO})$ nanostructures possessed $\mathrm{pH}$-responsive charge-conversional properties, due to the charge balance between carboxylic acid groups of glutamic acid residues and amines of lysine residues and PEI. In these $\mathrm{pH}$ conditions $(\mathrm{pH}$ 7.4 and 6.0$), \varepsilon$-amines of lysine and primary amines of PEI $(\mathrm{pKa}=\sim 10)$ would be almost protonated, contributing to the positive zeta-potential values of PKE(PEI-rGO) nanostructures, while carboxylic acid groups of glutamic acid residues and other amines of PEI (secondary and tertiary) would modulate net zeta-potential values, displaying $\mathrm{pH}$-dependent protonation/deprotonation behaviors. It was found that coating by $\mathrm{PK}_{5} \mathrm{E}_{5}$ polymer with the least glutamic acid portion and $\mathrm{PK}_{5} \mathrm{E}_{13}$ polymer with the most glutamic acid portion constructed positively-charged and negatively-charged nanostructures, respectively, at both $\mathrm{pH} 7.4$ and $\mathrm{pH}$ 6.0, which means that they lack $\mathrm{pH}$-responsive charge-conversional properties. Although the $\mathrm{PK}_{5} \mathrm{E}_{9}(\mathrm{PEI}-\mathrm{rGO})$ also exhibited the charge-conversional ability, it was presumed that the $\mathrm{PK}_{5} \mathrm{E}_{9}$ (PEI-rGO) nanostructure would be difficult to access to the cell membrane due to the large particle size and the low surface charge value at $\mathrm{pH}$ 6.0.

\subsection{Characterization of PKE(PEI-rGO/DOX)s}

First, the drug loading efficiency of PEI-rGO was assessed by measurement of absorbance and fluorescence of DOX-loaded PEI-rGO (PEI-rGO/DOX). As shown in Figure 3A, the characteristic absorbance peak of DOX was observed at $500 \mathrm{~nm}$ in PEI-rGO/DOX in contrast to PEI-rGO displaying no DOX peak, which means DOX molecules were successfully loaded on the surface of PEI-rGO by hydrophobic and $\pi-\pi$ stacking interaction between DOX and $\mathrm{rGO}$ as previously reported [33]. In fluorescence analysis (Figure 3B), the characteristic DOX fluorescence peaks were observed from PEI-rGO/DOX in 90\% DMSO condition, in contrast to water condition where no DOX peaks were 
found. This result confirmed that DOX molecules would be bound to rGO surface tightly in water, although they would be dissociated from rGO surface in $90 \%$ DMSO by interference of the interactions between DOX and rGO. Based on the fluorescence result, the DOX loading efficiency of PEI-rGO/DOX was determined as $82.0 \%$.
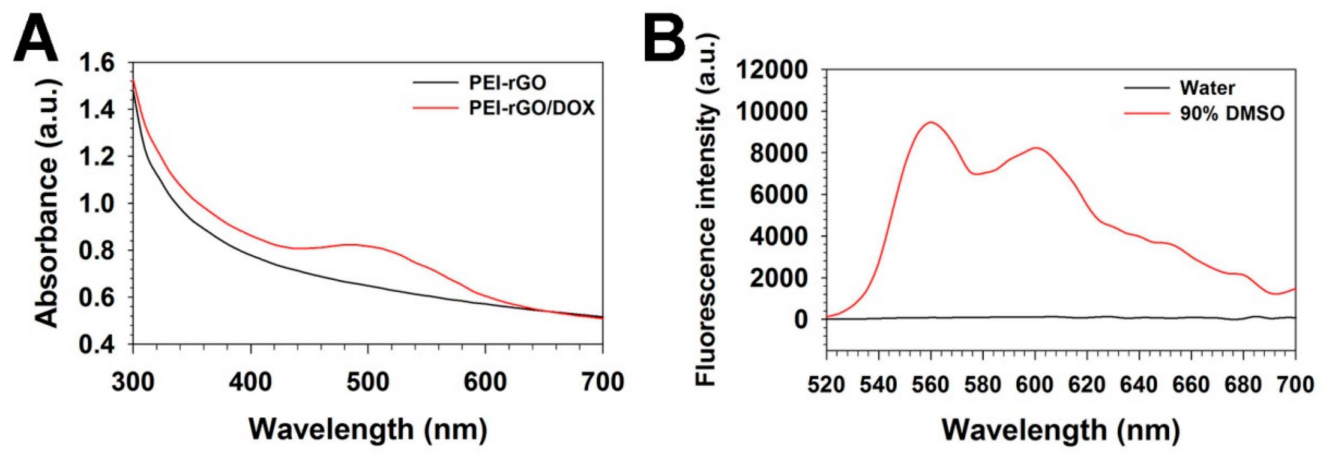

Figure 3. (A) Absorbance spectra of PEI-rGO (black) and PEI-rGO/DOX (red). (B) Fluorescence spectra of PEI-rGO/DOX in water (black) and 90\% DMSO (red).

To examine the DOX loading effect to PKE(PEI-rGO)s, the average sizes and zeta-potential values of PKE(PEI-rGO/DOX)s were measured at $\mathrm{pH} 7.4$ and 6.0 (Figure 4). The size of $\mathrm{PK}_{5} \mathrm{E}_{7}(\mathrm{PEI}-\mathrm{rGO} / \mathrm{DOX})$ was $1570 \mathrm{~nm}$ at $\mathrm{pH} 7.4$ and $762.0 \mathrm{~nm}$ at $\mathrm{pH}$ 6.0. Its zeta-potential value was $-13.1 \mathrm{mV}$ at $\mathrm{pH} 7.4$ and increased to $7.1 \mathrm{mV}$ at $\mathrm{pH}$ 6.0. $\mathrm{PK}_{5} \mathrm{E}_{9}(\mathrm{PEI}-\mathrm{rGO} / \mathrm{DOX})$ was found to have $182.5 \mathrm{~nm}$ size at $\mathrm{pH} 7.4$ and $889.9 \mathrm{~nm}$ at $\mathrm{pH}$ 6.0. Its zeta-potential was $-17.7 \mathrm{mV}$ at $\mathrm{pH} 7.4$ and increased to $-0.64 \mathrm{mV}$ at $\mathrm{pH} 6.0$. Considering the sizes and zeta-potential values of PKE(PEI-rGO) without DOX loading, a similar tendency responding to $\mathrm{pH}$ change was observed even after DOX loading. Since $\mathrm{PK}_{5} \mathrm{E}_{7}(\mathrm{PEI}-\mathrm{rGO} / \mathrm{DOX})$ showed suitable charge-conversion behavior from $\mathrm{pH} 7.4$ to 6.0, $\mathrm{PK}_{5} \mathrm{E}_{7}(\mathrm{PEI}-\mathrm{rGO} / \mathrm{DOX})$ was focused on for further characterization in this work.
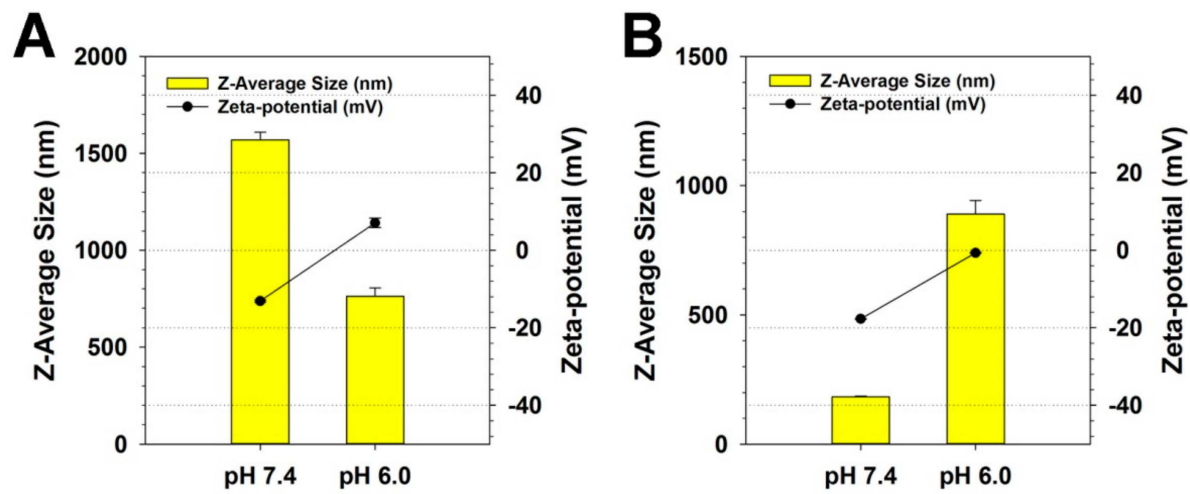

Figure 4. Z-average sizes and zeta-potential values of PKE(PEI-rGO/DOX) nanostructures at $\mathrm{pH} 7.4$ and 6.0. (A) $\mathrm{PK}_{5} \mathrm{E}_{7}(\mathrm{PEI}-\mathrm{rGO} / \mathrm{DOX})$ and (B) $\mathrm{PK}_{5} \mathrm{E}_{9}$ (PEI-rGO/DOX). The PKE polymer coating ratio was set to a weight ratio of 30 . Data are shown as the mean \pm S.D $(n=3)$.

The morphology of PEI-rGO nanostructures was observed by EF-TEM (Figure 5). In the case of PEI-rGO and PEI-rGO/DOX, plate-shaped nanostructures with sharp surfaces were observed (Figure $5 \mathrm{~A}, \mathrm{C}$ ), showing the typical morphology of $\mathrm{rGO}$. When the $\mathrm{PK}_{5} \mathrm{E}_{7}$ polymer was coated on PEI-rGO and PEI-rGO/DOX, spherical particles were observed (Figure 5B,D), showing a blurred edge characteristic of the polymer coating. This is a common phenomenon that occurs when carbon allotropes such as graphene or carbon nanotubes were coated or conjugated with polymers [30,33,36,37], which confirms that $\mathrm{PK}_{5} \mathrm{E}_{7}$ polymer was successfully coated on PEI-rGO and PEI-rGO/DOX. Additionally, the sizes of the nanostructures identified by TEM were approximately $300-400 \mathrm{~nm}$, which are similar to the sizes measured by the zeta-sizer. 


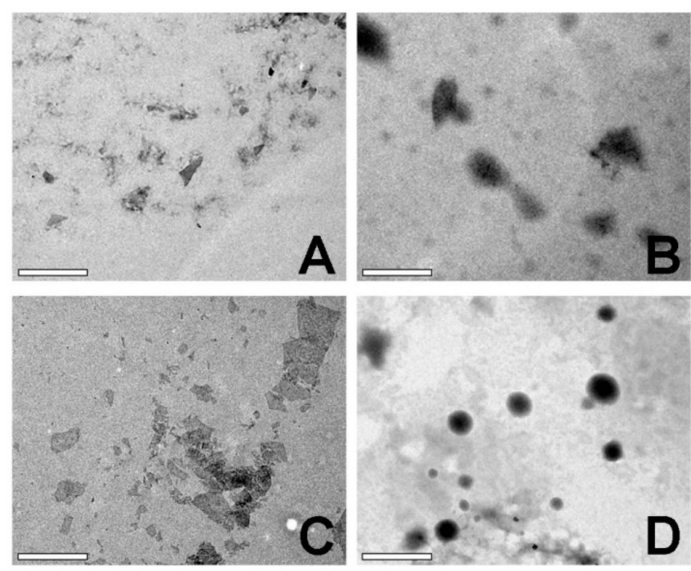

Figure 5. TEM images of (A) PEI-rGO, (B) $\mathrm{PK}_{5} \mathrm{E}_{7}$ (PEI-rGO), (C) PEI-rGO/DOX, and (D) $\mathrm{PK}_{5} \mathrm{E}_{7}(\mathrm{PEI}-\mathrm{rGO} / \mathrm{DOX})$. Scale bar $=0.5 \mu \mathrm{m}$.

\subsection{Serum Stability of $\mathrm{PK}_{5} E_{7}(\mathrm{PEI}-\mathrm{rGO})$}

In terms of drug or gene delivery systems, serum proteins in blood plasma are one of the most important obstacles to interrupt their therapeutic effects by the formation of large aggregates [38]. Therefore, the stability of $\mathrm{PK}_{5} \mathrm{E}_{7}(\mathrm{PEI}-\mathrm{rGO})$ nanostructure against serum proteins was examined by measuring its sizes under serum condition (10\% FBS). As shown in Figure 6, the sizes of PEI-rGO and $\mathrm{PK}_{5} \mathrm{E}_{7}(\mathrm{PEI}-\mathrm{rGO})$ gradually were increased until $4-8 \mathrm{~h}$ of incubation, showing the interaction with serum proteins. However, in the case of $\mathrm{PK}_{5} \mathrm{E}_{7}(\mathrm{PEI}-\mathrm{rGO})$, the size of the nanostructures was much smaller than that of uncoated PEI-rGO nanostructure at both $\mathrm{pH} 7.4$ and 6.0, meaning that PKE polymer coating could reduce the interaction with serum proteins. At $\mathrm{pH}$ 6.0, it was confirmed that the size of nanostructures was increased by increasing the electrostatic interaction of the positively-charged nanostructures with negatively-charged serum proteins, compared to the result at $\mathrm{pH}$ 7.4. The size of $\mathrm{PK}_{5} \mathrm{E}_{7}(\mathrm{PEI}-\mathrm{rGO})$ nanostructure was maintained as about $400 \mathrm{~nm}$ even after $24 \mathrm{~h}$ of incubation at $\mathrm{pH} 7.4$, showing its high serum stability. In the absence of serum (Figure S2), PEI-rGO and $\mathrm{PK}_{5} \mathrm{E}_{7}$ (PEI-rGO) showed similar sizes, although the sizes were increased in acidic condition probably due to the swelling by protonation of amines. Therefore, this result suggested that PEI-rGO nanostructure could be protected from non-specific interactions with anionic serum proteins at normal physiological $\mathrm{pH}$ via coating with charge-conversional $\mathrm{PK}_{5} \mathrm{E}_{7}$ polymer.

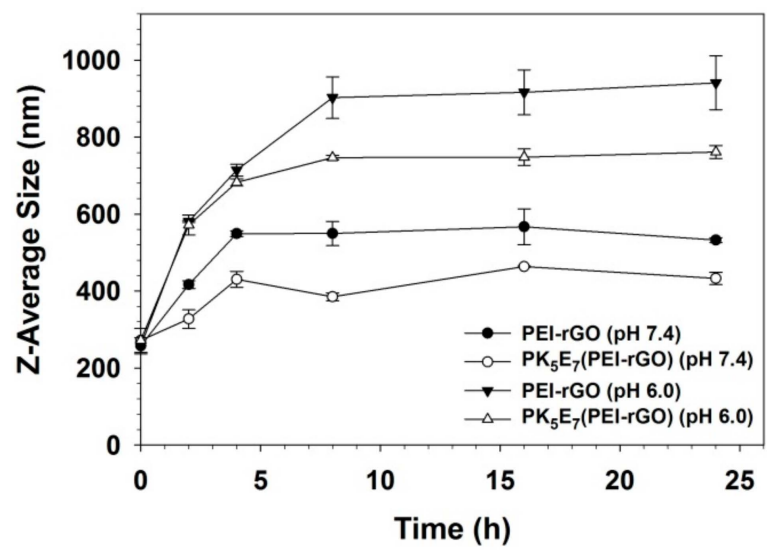

Figure 6. Z-average sizes of PEI-rGO and $\mathrm{PK}_{5} \mathrm{E}_{7}(\mathrm{PEI}-\mathrm{rGO})$ at $\mathrm{pH} 7.4$ and $\mathrm{pH} 6.0$ in serum condition $(10 \%$ FBS $)$. Data are shown as the mean \pm S.D $(n=3)$.

\subsection{DOX Release Profile of $\mathrm{PK}_{5} E_{7}(\mathrm{PEI}-\mathrm{rGO} / \mathrm{DOX})$}

The drug delivery systems should release their cargo drug molecules to the desired location of cells under various conditions. The DOX release behavior of $\mathrm{PK}_{5} \mathrm{E}_{7}(\mathrm{PEI}-\mathrm{rGO} / \mathrm{DOX})$ was investigated 
in three different conditions simulating the normal physiological condition ( $\mathrm{pH} 7.4)$, the lysosomal condition after endocytosis ( $\mathrm{pH}$ 5.0), and the lysosomal reducing condition after endocytosis ( $\mathrm{pH}$ 5.0, $5 \mathrm{mM} \mathrm{GSH}$ ) (Figure 7). DOX was released rapidly in all conditions until $2 \mathrm{~h}$ of incubation, meaning the initial burst release. After 2 h, DOX release at $\mathrm{pH} 7.4$ was gradually increased from $15.6 \%$ and maintained as about $22 \%$ after $24 \mathrm{~h}$, showing the lowest DOX release rate among all conditions. At $\mathrm{pH}$ 5.0, DOX release was increased, reaching about $27 \%$ after $24 \mathrm{~h}$. However, DOX release at $\mathrm{pH}$ 5.0 in the $5 \mathrm{mM}$ GSH condition was significantly higher $(36.3 \%, 24 \mathrm{~h})$ than DOX release at $\mathrm{pH} 7.4$ and $\mathrm{pH}$ 5.0. This DOX release result indicated the $\mathrm{pH}$ - and GSH-responsive DOX release behavior of the $\mathrm{PK}_{5} \mathrm{E}_{7}\left(\mathrm{PEI}-\mathrm{rGO} / \mathrm{DOX}\right.$ ) nanostructure. In the acidic condition, DOX, $\mathrm{PK}_{5} \mathrm{E}_{7}$, and PEI-rGO were positively charged and their electrostatic repulsion would weaken the interaction between bound DOX and PEI-rGO. Additionally, hydrogen bonding between rGO and DOX would be strong in the neutral condition, which can suppress DOX release at $\mathrm{pH} 7.4$ compared to $\mathrm{pH} 5.0$ [39]. Thus, DOX molecules would be easily released from $\mathrm{PK}_{5} \mathrm{E}_{7}(\mathrm{PEI}-\mathrm{rGO} / \mathrm{DOX})$ under the acidic condition.

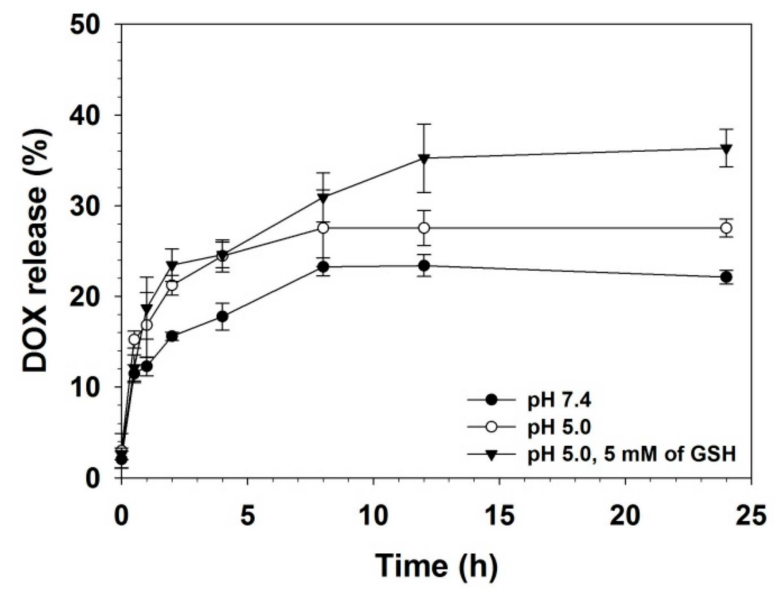

Figure 7. DOX release profile of $\mathrm{PK}_{5} \mathrm{E}_{7}(\mathrm{PEI}-\mathrm{rGO} / \mathrm{DOX})$ in various condition ( $\mathrm{pH} 7.4, \mathrm{pH}$ 5.0, and $\mathrm{pH}$ 5.0 with $5 \mathrm{mM}$ of GSH). Data are shown as the mean \pm S.D $(n=3)$.

DOX can be adsorbed on graphene materials via various mechanisms, such as $\pi-\pi$ interactions, hydrogen bonds, and hydrophobic interactions [39-41]. It was reported that an intracellular reducing agent, GSH, can disturb hydrophobic and aromatic interactions between DOX and PEI-rGO, inducing DOX release in cytosol [33,42]. Therefore, it was expected that $\mathrm{PK}_{5} \mathrm{E}_{7}(\mathrm{PEI}-\mathrm{rGO} / \mathrm{DOX})$ would release DOX efficiently after endocytosis, according to this result.

\subsection{Anticancer Activity of $\mathrm{PK}_{5} E_{7}(\mathrm{PEI}-\mathrm{rGO} / \mathrm{DOX})$}

Anticancer efficacy of $\mathrm{PK}_{5} \mathrm{E}_{7}(\mathrm{PEI}-\mathrm{rGO} / \mathrm{DOX})$ was validated by MTT assay in HeLa and A549 cells (Figure 8). First, the low cytotoxicity of $\mathrm{PK}_{5} \mathrm{E}_{7}$ (Figure $8 \mathrm{~A}, \mathrm{~B}$ ) and DOX-unloaded $\mathrm{PK}_{5} \mathrm{E}_{7}(\mathrm{PEI}-\mathrm{rGO})$ (Figure 8D), and well-known cytotoxicity of DOX only (Figure 8C), were identified in HeLa and A549 cells. PEI25k controls showed concentration-dependent high cytotoxicity. $\mathrm{PK}_{5} \mathrm{E}_{7}(\mathrm{PEI}-\mathrm{rGO} / \mathrm{DOX})$ showed DOX concentration-dependent decrease of cell viability in both serum-free and serum condition, regardless of cell types. Interestingly, much higher anticancer efficacy of $\mathrm{PK}_{5} \mathrm{E}_{7}(\mathrm{PEI}-\mathrm{rGO} / \mathrm{DOX})$ was observed at $\mathrm{pH} 6.0$ than $\mathrm{pH} 7.4$ in serum condition, although no significant change of cell viability was found in serum-free condition at both pH 7.4 and 6.0 in HeLa cells (Figure 8D,E). The similar pHand serum-responding anticancer activity behavior was also shown in A549 cells (Figure 8F,G). Lower anticancer activity of $\mathrm{PK}_{5} \mathrm{E}_{7}(\mathrm{PEI}-\mathrm{rGO} / \mathrm{DOX})$ than DOX only was probably due to the slow release of DOX from the nanocarrier [43] and the association of released DOX molecules with negatively-charged $\mathrm{PK}_{5} \mathrm{E}_{7}$ polymers [44]. In addition, in the cased of DOX only, cells are exposed directly to DOX molecules with high concentration. However, without proper delivery systems possessing solvation and targeting ability, DOX concentration would be found to be very low in tumor tissue under in vivo 
conditions. It was also reported that free DOX could induce serious heart damage [45] and multi-drug resistance (MDR) of cancer cells could decrease the therapeutic effect by exporting internalized free DOX molecules [46] and that DOX-loaded nanocarriers could overcome MDR of cancer cells $[47,48]$.
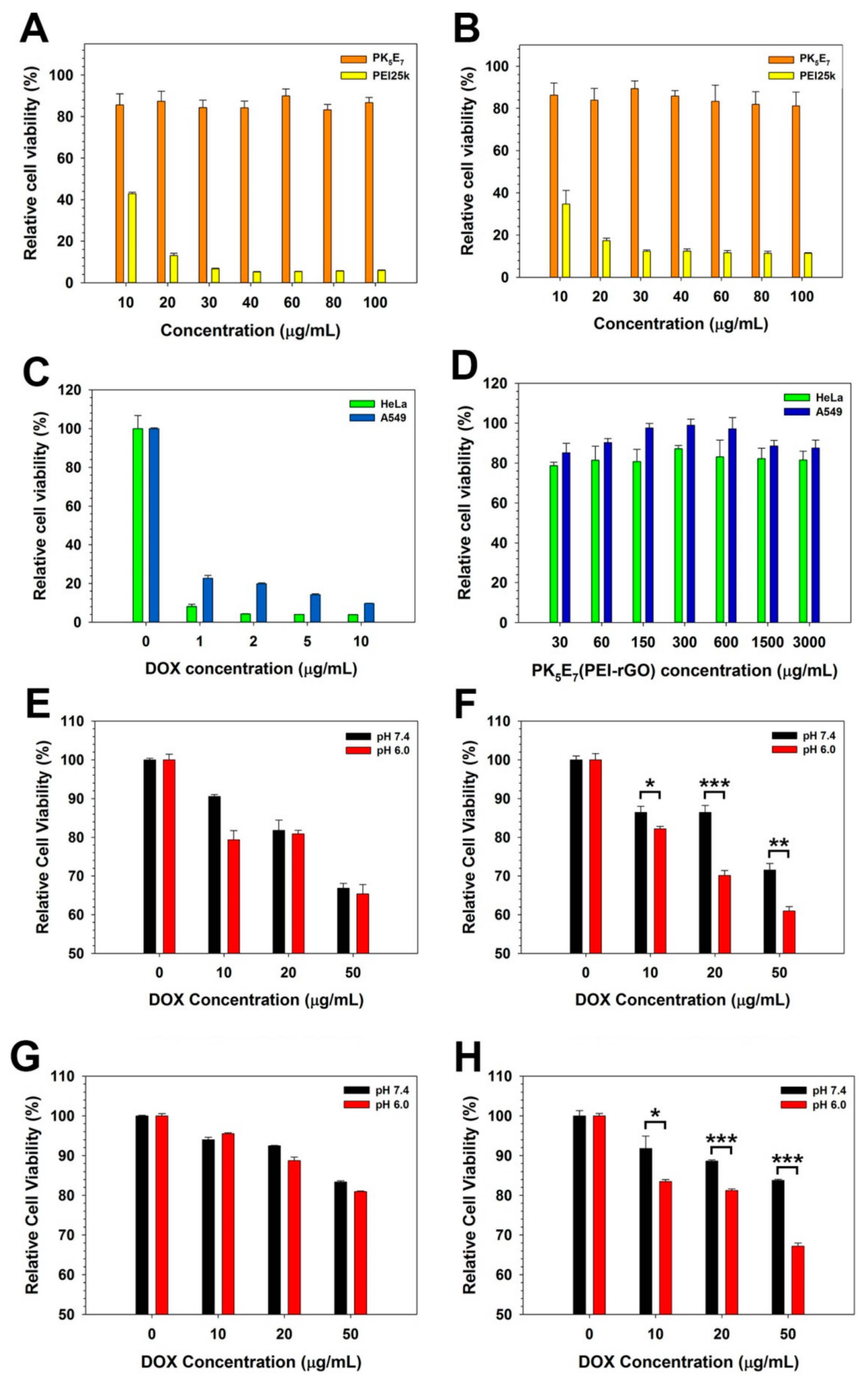

Figure 8. Cytotoxicity results of $\mathrm{PK}_{5} \mathrm{E}_{7}$ in HeLa cells (A) and A549 cells (B). PEI25k was used as a control. Anticancer activity of DOX only in HeLa and A549 cells (C). Cytotoxicity results of DOX-unloaded $\mathrm{PK}_{5} \mathrm{E}_{7}(\mathrm{PEI}-\mathrm{rGO})$ in HeLa and A549 cells (D). Anticancer activity of $\mathrm{PK}_{5} \mathrm{E}_{7}$ (PEI-rGO/DOX) in HeLa $(\mathbf{E}, \mathbf{F})$ and A549 cells $(\mathbf{G}, \mathbf{H})$. The experiments were conducted in serum-free $(\mathbf{E}, \mathbf{G})$ and serum (10\% FBS) condition $(\mathbf{F}, \mathbf{H})$. Data are shown as the mean \pm S.D $(n=3)$ and statistically analyzed by $t$-test $\left({ }^{*} p<0.05\right.$, ${ }^{* *} p<0.01$, and ${ }^{* * *} p<0.001$ ). 
Contrary to $\mathrm{pH} 7.4$, anionic serum proteins such as albumin would bind to $\mathrm{PK}_{5} \mathrm{E}_{7}$ (PEI-rGO/DOX) at $\mathrm{pH} 6.0$ due to its $\mathrm{pH}$-responsive charge-conversion, according to the former results. Previously, it was reported that the human serum albumin (HAS)-coated lipoplexes could bind non-specifically to cell surface receptors, analogous to scavenger receptors, which mediate their endocytosis [49]. Another report also indicated the ability of albumin to promote membrane fusion under acidic conditions [50]. Therefore, it was suggested that albumin-decorated $\mathrm{PK}_{5} \mathrm{E}_{7}(\mathrm{PEI}-\mathrm{rGO} / \mathrm{DOX})$ could bind to cell membranes non-specifically at $\mathrm{pH} 6.0$ in serum condition, which would induce its facilitated endocytosis and DOX delivery to cancer cells, finally leading to the high anticancer activity. In addition, the increased DOX efficacy in acidic environment was probably due to the expedited DOX release from $\mathrm{PK}_{5} \mathrm{E}_{7}(\mathrm{PEI}-\mathrm{rGO})$ in acidic condition as shown in Figure 7. Therefore, it is expected that the $\mathrm{PK}_{5} \mathrm{E}_{7}(\mathrm{PEI}-\mathrm{rGO} / \mathrm{DOX})$ nanostructure would show an enhanced cancer cell killing effect in the acidic tumor microenvironment condition via aid of decorated serum proteins, maintaining the intact status under normal physiological condition.

\subsection{Cellular Uptake of $P K_{5} E_{7}(P E I-r G O / D O X)$}

Flow cytometry analysis was performed to elucidate the $\mathrm{pH}$ and serum effect onto the cellular uptake of $\mathrm{PK}_{5} \mathrm{E}_{7}$ (PEI-rGO/DOX) in HeLa and A549 cells (Figure S3). In HeLa cells (serum-free condition, Figure S3A), the cellular uptake efficiency of $\mathrm{PK}_{5} \mathrm{E}_{7}(\mathrm{PEI}-\mathrm{rGO} / \mathrm{DOX})$ was $10.1 \%$ at $\mathrm{pH} 7.4$ and it was decreased to $8.1 \%$ at $\mathrm{pH}$ 6.0. However, in the presence of serum (Figure S3C), the uptake efficiency was increased from 7.9\% ( $\mathrm{pH} 7.4$ ) to $20.6 \%$ ( $\mathrm{pH}$ 6.0). In A549 cells, similar cellular uptake behavior of $\mathrm{PK}_{5} \mathrm{E}_{7}(\mathrm{PEI}-\mathrm{rGO} / \mathrm{DOX})$ was observed. The uptake efficiency was $27.8 \%$ at $\mathrm{pH} 7.4$ and decreased to $8.1 \%$ at $\mathrm{pH} 6.0$ in serum-free condition (Figure S3B). In serum condition (Figure S3D), it was increased from $18.6 \%$ ( $\mathrm{pH} 7.4$ ) to $31.8 \%$ ( $\mathrm{pH}$ 6.0). These cellular uptake results were well correlated to the above anticancer activity of $\mathrm{PK}_{5} \mathrm{E}_{7}$ (PEI-rGO/DOX).

In the serum-free condition, it was thought that relatively lower cellular uptake efficiency of $\mathrm{PK}_{5} \mathrm{E}_{7}(\mathrm{PEI}-\mathrm{rGO} / \mathrm{DOX})$ at $\mathrm{pH} 6.0$ than $\mathrm{pH} 7.4$ would be induced by decelerated overall cellular activity [51] and by charge repulsion between positively-charged cell surface [52] and $\mathrm{PK}_{5} \mathrm{E}_{7}$ (PEI-rGO/DOX) in acidic condition.

Interestingly, 1.7 2.6 times increased cellular uptake efficiency of $\mathrm{PK}_{5} \mathrm{E}_{7}(\mathrm{PEI}-\mathrm{rGO} / \mathrm{DOX})$ at $\mathrm{pH} 6.0$ in serum condition in comparison with the efficiency at $\mathrm{pH}$ 7.4, suggested that serum-protein-decorated $\mathrm{PK}_{5} \mathrm{E}_{7}(\mathrm{PEI}-\mathrm{rGO} / \mathrm{DOX})$ by electrostatic interaction via charge-conversion would be internalized into cells more efficiently through non-specific interaction of albumin with cell membrane, overcoming the decelerated overall cellular activity and charge repulsion between positively-charged cell surface and $\mathrm{PK}_{5} \mathrm{E}_{7}$ (PEI-rGO/DOX) in acidic condition.

Cellular uptake behaviors of $\mathrm{PK}_{5} \mathrm{E}_{7}(\mathrm{PEI}-\mathrm{rGO} / \mathrm{DOX})$ nanostructures were further observed by fluorescence microscopy (Figure 9). It was found that PEI-rGO/DOX could be internalized into cells even after $\mathrm{PK}_{5} \mathrm{E}_{7}$ polymer coating and that especially, in the acidic tumor microenvironment condition (serum, $\mathrm{pH}$ 6.0), $\mathrm{PK}_{5} \mathrm{E}_{7}(\mathrm{PEI}-\mathrm{rGO} / \mathrm{DOX}$ ) displayed the highest cellular uptake activity, as shown in flow cytometry analysis result.

Overall, the scheme for the formation of PKE(PEI-rGO/DOX) nanostructures and their serum stability and decorated serum protein-mediated cellular uptake by PKE coating is presented in Figure S4. 


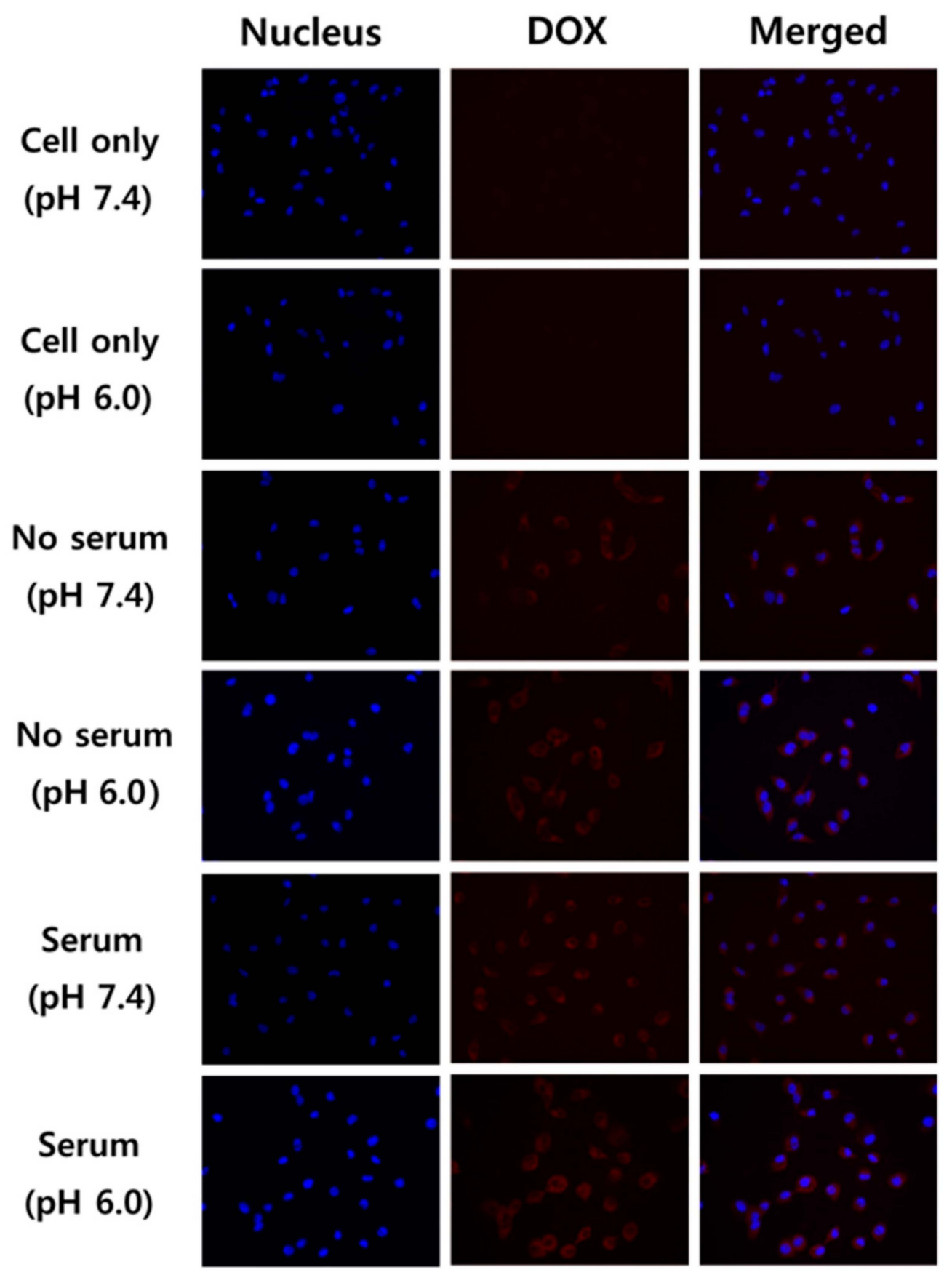

Figure 9. Fluorescence microscopy images of $\mathrm{PK}_{5} \mathrm{E}_{7}(\mathrm{PEI}-\mathrm{rGO} / \mathrm{DOX})$ in $\mathrm{A} 549$ cells.

\section{Conclusions}

In this work, DOX-loaded PEI-rGO was coated with pH-responsive charge-conversional polymer, PKE polymer, forming PKE(PEI-rGO/DOX) nanostructures and investigated for drug delivery systems. The $\mathrm{pH}$-responsive charge-conversional property of $\mathrm{PK}_{5} \mathrm{E}_{7}(\mathrm{PEI}-\mathrm{rGO})$ was identified by zeta-potential value measurement. The sharp-edged sheet structure of PEI-rGO was transformed to spherical nanostructures with vague edges by $\mathrm{PK}_{5} \mathrm{E}_{7}$ coating. It was also found that $\mathrm{PK}_{5} \mathrm{E}_{7}$ coating could endow the stability against serum proteins to $\mathrm{PK}_{5} \mathrm{E}_{7}(\mathrm{PEI}-\mathrm{rGO})$ nanostructure. Loaded doxorubicin (DOX) in $\mathrm{PK}_{5} \mathrm{E}_{7}$ (PEI-rGO) could be released rapidly in lysosomal condition ( $\mathrm{pH}$ 5.0, $5 \mathrm{mM}$ glutathione). Furthermore, DOX-loaded $\mathrm{PK}_{5} \mathrm{E}_{7}(\mathrm{PEI}-\mathrm{rGO}$ ) showed enhanced anticancer activity in cancer cells in tumor microenvironment-mimicking condition, which would be facilitated by improved cellular uptake via non-specific cellular interaction with decorated serum proteins. Therefore, $\mathrm{pH}$-responsive 
charge-conversional PKE polymer-coating strategy of cationic nanostructures is thought to possess a potential for tumor microenvironment-targeted drug delivery systems.

Supplementary Materials: The following are available online at http://www.mdpi.com/2079-4991/9/9/1289/s1, Figure S1. Size distribution histograms of $\mathrm{PK}_{5} \mathrm{E}_{7}(\mathrm{PEI}-\mathrm{rGO})$ nanostructures, Figure S2. Z-average sizes of PEI-rGO and $\mathrm{PK}_{5} \mathrm{E}_{7}(\mathrm{PEI}-\mathrm{rGO})$ at $\mathrm{pH} 7.4$ and $\mathrm{pH}$ 6.0 in PBS buffer, Figure S3. Cellular uptake analysis of $\mathrm{PK}_{5} \mathrm{E}_{7}$ (PEI-rGO/DOX) by flow cytometry in HeLa and A549 cells, Figure S4. The scheme for the formation of PKE(PEI-rGO/DOX) nanostructures and their serum stability and decorated serum protein-mediated cellular uptake by PKE coating.

Author Contributions: Conceptualization: T.-i.K.; investigation: K.R. and J.P.; methodology: K.R. and J.P.; writing-original draft preparation: K.R.; writing—review and editing: T.-i.K.; supervision and project administration: T.-i.K.

Funding: This work was supported by Basic Science Research Program through the National Research Foundation of Korea (NRF) funded by the Ministry of Science, ICT \& Future Planning (NRF-2014R1A1A1037692) and by the Ministry of Education (NRF-2017R1D1A1B03030556), and by Promising-Pioneering Researcher Program through Seoul National University (SNU) in 2015.

Conflicts of Interest: The authors declare no conflict of interest.

\section{References}

1. Li, H.; Fan, X.; Houghton, J. Tumor microenvironment: The role of the tumor stroma in cancer. J. Cell. Biochem. 2007, 101, 805-815. [CrossRef] [PubMed]

2. Mbeunkui, F.; Johann, D.J. Cancer and the tumor microenvironment: A review of an essential relationship. Cancer Chemoth. Pharm. 2009, 63, 571-582. [CrossRef] [PubMed]

3. Zhao, G.; Rodriguez, B.L. Molecular targeting of liposomal nanoparticles to tumor microenvironment. Int. J. Nanomed. 2013, 8, 61-71. [CrossRef] [PubMed]

4. Sounni, N.E.; Noel, A. Targeting the tumor microenvironment for cancer therapy. Clin. Chem. 2013, 59, 85-93. [CrossRef] [PubMed]

5. Tannock, I.F.; Rotin, D. Acid pH in tumors and its potential for therapeutic exploitation. Cancer Res. 1989, 49, 4373-4384. [PubMed]

6. Gerweck, L.E.; Seetharaman, K. Cellular pH gradient in tumor versus normal tissue: Potential exploitation for the treatment of cancer. Cancer Res. 1996, 56, 1194-1198. [PubMed]

7. Swietach, P.; Vaughan-Jones, R.D.; Harris, A.L.; Hulikova, A. The chemistry, physiology and pathology of pH in cancer. Philos. T. Roy. Soc. B 2014, 369, 20130099. [CrossRef]

8. Marrack, J.; Hoch, H. Serum proteins: A review. J. Clin. Pathol. 1949, 2, 161. [CrossRef]

9. De Smedt, S.C.; Demeester, J.; Hennink, W.E. Cationic polymer based gene delivery systems. Pharm. Res. 2000, 17, 113-126. [CrossRef]

10. Lee, Y.; Miyata, K.; Oba, M.; Ishii, T.; Fukushima, S.; Han, M.; Koyama, H.; Nishiyama, N.; Kataoka, K. Charge-Conversion Ternary Polyplex with Endosome Disruption Moiety: A Technique for Efficient and Safe Gene Delivery. Angew. Chem. Int. Edit. 2008, 120, 5241-5244. [CrossRef]

11. Kim, S.; Lee, D.J.; Kwag, D.S.; Lee, U.Y.; Youn, Y.S.; Lee, E.S. Acid pH-activated glycol chitosan/fullerene nanogels for efficient tumor therapy. Carbohyd. Polym. 2014, 101, 692-698. [CrossRef] [PubMed]

12. Yuan, F.; Wang, S.; Chen, G.; Tu, K.; Jiang, H.; Wang, L.-Q. Novel chitosan-based pH-sensitive and disintegrable polyelectrolyte nanogels. Colloid. Surface. B 2014, 122, 194-201. [CrossRef] [PubMed]

13. Kang, S.; Kim, Y.; Song, Y.; Choi, J.U.; Park, E.; Choi, W.; Park, J.; Lee, Y. Comparison of pH-sensitive degradability of maleic acid amide derivatives. Bioorg. Med. Chem. Lett. 2014, 24, 2364-2367. [CrossRef] [PubMed]

14. Zhou, Z.; Murdoch, W.J.; Shen, Y. A linear polyethylenimine (LPEI) drug conjugate with reversible charge to overcome multidrug resistance in cancer cells. Polymer 2015, 76, 150-158. [CrossRef]

15. Jiang, L.; Li, L.; He, X.; Yi, Q.; He, B.; Cao, J.; Pan, W.; Gu, Z. Overcoming drug-resistant lung cancer by paclitaxel loaded dual-functional liposomes with mitochondria targeting and $\mathrm{pH}$-response. Biomaterials 2015, 52, 126-139. [CrossRef] [PubMed]

16. Lee, Y.; Fukushima, S.; Bae, Y.; Hiki, S.; Ishii, T.; Kataoka, K. A protein nanocarrier from charge-conversion polymer in response to endosomal pH. J. Am. Chem. Soc. 2007, 129, 5362-5363. [CrossRef] [PubMed] 
17. Zhou, T.; Zhou, X.; Xing, D. Controlled release of doxorubicin from graphene oxide based charge-reversal nanocarrier. Biomaterials 2014, 35, 4185-4194. [CrossRef] [PubMed]

18. Prabaharan, M.; Grailer, J.J.; Pilla, S.; Steeber, D.A.; Gong, S. Amphiphilic multi-arm-block copolymer conjugated with doxorubicin via $\mathrm{pH}$-sensitive hydrazone bond for tumor-targeted drug delivery. Biomaterials 2009, 30, 5757-5766. [CrossRef] [PubMed]

19. Liu, P.; Wu, Q.; Li, Y.; Li, P.; Yuan, J.; Meng, X.; Xiao, Y. DOX-Conjugated Keratin Nanoparticles for pH-Sensitive Drug Delivery. Colloid. Surface. B 2019, 181, 1012-1018. [CrossRef] [PubMed]

20. Xu, J.; Qin, B.; Luan, S.; Qi, P.; Wang, Y.; Wang, K.; Song, S. Acid-labile poly (ethylene glycol) shell of hydrazone-containing biodegradable polymeric micelles facilitating anticancer drug delivery. J. Bioact. Compat. Pol. 2018, 33, 119-133. [CrossRef]

21. Ding, X.; Liu, Y.; Li, J.; Luo, Z.; Hu, Y.; Zhang, B.; Liu, J.; Zhou, J.; Cai, K. Hydrazone-bearing PMMA-functionalized magnetic nanocubes as $\mathrm{pH}$-responsive drug carriers for remotely targeted cancer therapy in vitro and in vivo. ACS Appl. Mater. Inter. 2014, 6, 7395-7407. [CrossRef] [PubMed]

22. Xia, J.; Chen, J.; Tian, H.; Chen, X. Synthesis and characterization of a pH-sensitive shielding system for polycation gene carriers. Sci. China Chem. 2010, 53, 502-507. [CrossRef]

23. Tian,H.; Guo, Z.; Lin, L.; Jiao, Z.; Chen, J.; Gao, S.; Zhu, X.; Chen, X.pH-responsive zwitterionic copolypeptides as charge conversional shielding system for gene carriers. J. Control. Release 2014, 174, 117-125. [CrossRef] [PubMed]

24. Lv, S.; Song, W.; Tang, Z.; Li, M.; Yu, H.; Hong, H.; Chen, X. Charge-conversional PEG-polypeptide polyionic complex nanoparticles from simple blending of a pair of oppositely charged block copolymers as an intelligent vehicle for efficient antitumor drug delivery. Mol. Pharm. 2014, 11, 1562-1574. [CrossRef] [PubMed]

25. Guan, X.; Li, Y.; Jiao, Z.; Lin, L.; Chen, J.; Guo, Z.; Tian, H.; Chen, X. Codelivery of antitumor drug and gene by a $\mathrm{pH}$-sensitive charge-conversion system. ACS Appl. Mater. Inter. 2015, 7, 3207-3215. [CrossRef] [PubMed]

26. Chen, J.; Dong, X.; Feng, T.; Lin, L.; Guo, Z.; Xia, J.; Tian, H.; Chen, X. Charge-conversional zwitterionic copolymer as $\mathrm{pH}$-sensitive shielding system for effective tumor treatment. Acta Biomater. 2015, 26, 45-53. [CrossRef] [PubMed]

27. Ryu, K.; Lee, M.K.; Park, J.; Kim, T.-I. pH-Responsive Charge-Conversional Poly (ethylene imine)-Poly (1-lysine)-Poly (1-glutamic acid) with Self-Assembly and Endosome Buffering Ability for Gene Delivery Systems. ACS Appl. Bio Mater. 2018, 1, 1496-1504. [CrossRef]

28. Zhu, Y.; Murali, S.; Cai, W.; Li, X.; Suk, J.W.; Potts, J.R.; Ruoff, R.S. Graphene and graphene oxide: Synthesis, properties, and applications. Adv. Mater. 2010, 22, 3906-3924. [CrossRef] [PubMed]

29. Hummers, W.S., Jr.; Offeman, R.E. Preparation of graphitic oxide. J. Am. Chem. Soc. 1958, 80, 1339. [CrossRef]

30. Sun, X.; Liu, Z.; Welsher, K.; Robinson, J.T.; Goodwin, A.; Zaric, S.; Dai, H. Nano-graphene oxide for cellular imaging and drug delivery. Nano Res. 2008, 1, 203-212. [CrossRef]

31. Shim, G.; Kim, M.-G.; Park, J.Y.; Oh, Y.-K. Graphene-based nanosheets for delivery of chemotherapeutics and biological drugs. Adv. Drug Deliver. Rev. 2016, 105, 205-227. [CrossRef] [PubMed]

32. Kim, H.; Namgung, R.; Singha, K.; Oh, I.-K.; Kim, W.J. Graphene oxide-polyethylenimine nanoconstruct as a gene delivery vector and bioimaging tool. Bioconj. Chem. 2011, 22, 2558-2567. [CrossRef] [PubMed]

33. Kim, H.; Lee, D.; Kim, J.; Kim, T.-I.; Kim, W.J. Photothermally triggered cytosolic drug delivery via endosome disruption using a functionalized reduced graphene oxide. ACS Nano 2013, 7, 6735-6746. [CrossRef] [PubMed]

34. Lomovskaya, N.; Otten, S.L.; Doi-Katayama, Y.; Fonstein, L.; Liu, X.-C.; Takatsu, T.; Inventi-Solari, A.; Filippini, S.; Torti, F.; Colombo, A.L.; et al. Doxorubicin overproduction in Streptomyces peucetius: Cloning and characterization of the dnrU ketoreductase and $\mathrm{dnrV}$ genes and the doxA cytochrome P-450 hydroxylase gene. J. Bacteriol. 1999, 181, 305-318. [PubMed]

35. Hsieh, A.G.; Korkut, S.; Punckt, C.; Aksay, I.A. Dispersion stability of functionalized graphene in aqueous sodium dodecyl sulfate solutions. Langmuir 2013, 29, 14831-14838. [CrossRef] [PubMed]

36. Nguyen, D.; Such, C.H.; Hawkett, B.S. Polymer coating of carboxylic acid functionalized multiwalled carbon nanotubes via reversible addition-fragmentation chain transfer mediated emulsion polymerization. J. Polym. Sci. Pol. Chem. 2013, 51, 250-257. [CrossRef] 
37. Huynh, V.T.; Nguyen, D.; Such, C.H.; Hawkett, B.S. Polymer coating of graphene oxide via reversible addition-fragmentation chain transfer mediated emulsion polymerization. J. Polym. Sci. Pol. Chem. 2015, 53, 1413-1421. [CrossRef]

38. Goldman, C.K.; Soroceanu, L.; Smith, N.; Gillespie, G.Y.; Shaw, W.; Burgess, S.; Bilbao, G.; Curiel, D.T. In vitro and in vivo gene delivery mediated by a synthetic polycationic amino polymer. Nat. Biotechnol. 1997, 15, 462. [CrossRef]

39. Yang, X.; Zhang, X.; Liu, Z.; Ma, Y.; Huang, Y.; Chen, Y. High-efficiency loading and controlled release of doxorubicin hydrochloride on graphene oxide. J. Phys. Chem. C 2008, 112, 17554-17558. [CrossRef]

40. Zhang, R.; Olin, H. Carbon nanomaterials as drug carriers: Real time drug release investigation. Mat. Sci. Eng. C-Mater. 2012, 32, 1247-1252. [CrossRef]

41. Zhang, L.; Xia, J.; Zhao, Q.; Liu, L.; Zhang, Z. Functional graphene oxide as a nanocarrier for controlled loading and targeted delivery of mixed anticancer drugs. Small 2010, 6, 537-544. [CrossRef] [PubMed]

42. Dembereldorj, U.; Kim, M.; Kim, S.; Ganbold, E.-O.; Lee, S.Y.; Joo, S.-W. A spatiotemporal anticancer drug release platform of PEGylated graphene oxide triggered by glutathione in vitro and in vivo. J. Mater. Chem. 2012, 22, 23845-23851. [CrossRef]

43. Lee, Y.; Jung, G.-E.; Cho, S.J.; Geckeler, K.E.; Fuchs, H. Cellular interactions of doxorubicin-loaded DNA-modified halloysite nanotubes. Nanoscale 2013, 5, 8577-8585. [CrossRef] [PubMed]

44. Tu, Z.; Wycisk, V.; Cheng, C.; Chen, W.; Adeli, M.; Haag, R. Functionalized graphene sheets for intracellular controlled release of therapeutic agents. Nanoscale 2017, 9, 18931-18939. [CrossRef] [PubMed]

45. Swain, S.M.; Whaley, F.S.; Ewer, M.S. Congestive heart failure in patients treated with doxorubicin. Cancer 2003, 97, 2869-2879. [CrossRef] [PubMed]

46. Gillet, J.-P.; Gottesman, M.M. Mechanisms of multidrug resistance in cancer. Methods Mol. Biol. 2010, 596, 47-76. [PubMed]

47. Amirmahani, N.; Mahmoodi, N.O.; Galangash, M.M.; Ghavidast, A. Advances in nanomicelles for sustained drug delivery. J. Ind. Eng. Chem. 2017, 55, 21-34. [CrossRef]

48. Kim, T.; Park, J.; Kim, T.-I. Cholic acid-conjugated methylcellulose-polyethylenimine nano-aggregates for drug delivery systems. Nanomaterials 2019, 9, 459. [CrossRef] [PubMed]

49. Simões, S.; Slepushkin, V.; Pires, P.; Gaspar, R.; Pedroso de Lima, M.C.; Düzgüneş, N. Human serum albumin enhances DNA transfection by lipoplexes and confers resistance to inhibition by serum. BBA-Biomembranes 2000, 1463, 459-469. [CrossRef]

50. Shenkman, S.; Araujo, P.S.; Dijkman, R.; Quina, F.H.; Chaimovich, H. Effects of temperature and lipid composition on the serum albumin-induced aggregation and fusion of small unilamellar vesicles. Biochim. Biophys. Acta 1981, 649, 633-641. [CrossRef]

51. Kang, H.C.; Samsonova, O.; Kang, S.W.; Bae, Y.H. The effect of environmental pH on polymeric transfection efficiency. Biomaterials 2012, 33, 1651-1662. [CrossRef] [PubMed]

52. Loufakis, D.N.; Cao, Z.; Ma, S.; Mittelman, D.; Lu, C. Focusing of mammalian cells under an ultrahigh $\mathrm{pH}$ gradient created by unidirectional electropulsation in a confined microchamber. Chem. Sci. 2014, 5, 3331-3337. [CrossRef] [PubMed]

(C) 2019 by the authors. Licensee MDPI, Basel, Switzerland. This article is an open access article distributed under the terms and conditions of the Creative Commons Attribution (CC BY) license (http://creativecommons.org/licenses/by/4.0/). 